Moran Campbell

\section{Moran Campbell and clinical science} G J Gibson

W ith the recent death of $\mathrm{E} J \mathrm{M}$ (Moran) Campbell, respiratory medicine lost one of its most notable figures of the last 50 years. Moran Campbell graduated in medicine from the Middlesex Hospital London in 1949 following a career defining intercalated BSc in physiology. He then worked as a researcher and clinician at the Middlesex and later at the Royal Postgraduate Medical School and Hammersmith Hospital, with a short period of research in the laboratory of R L Riley at Johns Hopkins Hospital, Baltimore. In 1968 he emigrated to Canada to become the first chairman of the Department of Medicine in the new medical school at McMaster University, Hamilton, Ontario. He retired in 1991 but continued to teach and to take an active interest in research until shortly before his death.

Campbell's main research contributions were made when working in England in the 1950s and 1960s. His very readable memoirs ${ }^{1}$ convey the excitement of clinical research at a time when scientific principles were gradually being applied to clinical medicine. His curiosity was stimulated by observations in patients with respiratory disease and his research was very much aimed at understanding and solving clinical problems. Of his three main research interests, his work on the respiratory muscles developed from questioning the therapeutic benefit of breathing exercises; he addressed the most distressing symptom experienced by patients with lung disease and, above all, he was driven by the practical need to understand and improve the management of respiratory failure. In all these areas his work remains highly relevant today.

Campbell strongly urged the integration of physiology into clinical medicine, co-editing with C J (John) Dickinson a very successful textbook ${ }^{2}$ which did precisely that. He later ventured the view $^{3}$ that "my good fortune in having the requisite grasp of physiology and sufficient clinical experience enabled me to have ideas that would not have come from collaboration with a better physiologist and a better clinician". He pointed to the danger of respiratory physiology becoming too abstruse and detached from clinical reality: reviewing a textbook of cardiorespiratory physiology, he deprecated "the tendency to foster a priesthood of respiratory physiologists" and in this context he contrasted the situation with that in cardiology: "Cardiologists are, of course, not inclined to refer patients to the physiology laboratory for "cardiac function tests and the opinion of a cardiac physiologist" so the danger is less in that field".

Campbell's teaching, like his writing, was forthright and inspiring and was peppered with colourful metaphors (the $\mathrm{FEV}_{1}$ was "a bronchopulmonary fart"). In his later career he took a major interest in medical education-both undergraduate and postgraduate-and his views on the role of science in medicine make stimulating reading.

\section{RESPIRATORY MUSCLES AND BREATHLESSNESS}

Campbell's first major research related to the actions of the respiratory muscles. He undertook the first detailed investigations of EMG activity and the mechanical actions of individual inspiratory and expiratory muscles in healthy subjects and disease. ${ }^{5-8}$ These studies comprised his $\mathrm{PhD}$ thesis and

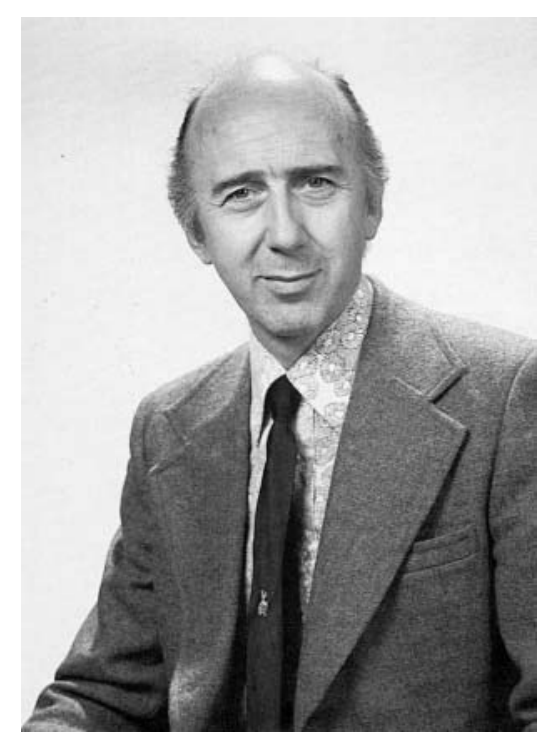

Moran Campbell (1925-2004) were later expanded into a classic monograph ${ }^{9}$ - the first comprehensive review of the subject in the modern era. His method of displaying the static and dynamic pressures generated by the different components of the respiratory system (the Campbell diagram) remains a standard way of analysing respiratory mechanics and muscle energetics. This pioneering work set the scene for an enormous volume of research over the next 50 years on the respiratory muscles in health and disease.

The work of Campbell and J B L (Jack) Howell on breathlessness and their concept of "length-tension inappropriateness" ${ }^{\prime 10}$ developed from experiments on the factors controlling the length of breath holding and the ability of subjects to detect added loads to breathing. The most dramatic evidence supporting the hypothesis came later with heroic experiments involving the curarisation of healthy volunteers (including Campbell himself). ${ }^{11}$ These studies showed that muscle paralysis greatly extended the period for which an individual could be apnoeic without distress (at least to the subject, if not to the observers ${ }^{1}$ ). They thus confirmed that the discomfort of breath holding was dependent on respiratory muscle activity. These ideas represented what would now be termed a "paradigm shift", in that they turned attention to breathlessness as a function of the balance between the effort involved in breathing and the mechanical output of respiratory muscle activity. The hypothesis of length-tension inappropriateness stimulated considerable interest but was interpreted too specifically by some. Indeed, early on, Campbell and Howell $^{12}$ cautioned against too literal an interpretation of the concept, warning "a respiratory physiologist offering a unitary explanation for breathlessness should arouse the same suspicions as a tattooed archbishop offering a free ticket to heaven". Campbell later suggested that the less specific "mechanical inappropriateness" was preferable. ${ }^{13}$ In simple terms, the effort of breathing can appear inappropriate either because it is disproportionate to the output (for example, in acute asthma - "difficulty in breathing") or because both output and demand are excessive (for example, at altitude - "breathing too much"). In many patients with lung disease both mechanisms may operate.

\section{RESPIRATORY FAILURE AND CONTROLLED OXYGEN}

By the 1950s the problem of hypercapnic respiratory failure due to exacerbations of "chronic bronchitis" was increasingly recognised in British hospitals, particularly in the winter months. 
The increasing prevalence was a consequence of the dramatic increase in cigarette smoking over the preceding 30 years plus the effect of the notorious winter smogs. As Campbell relates, ${ }^{1}$ these patients at first received little attention, particularly in teaching hospitals, as they were not regarded as "interesting" and their treatment was unrewarding. Patients were sometimes treated in oxygen tents in which they might become "pink and peaceful", but frequently this led to "a slumber which was irreversible". Consequently "from being victims of neglect they became victims of enthusiasm". One popular approach aimed at avoiding progressive hypercapnia was to use intermittent oxygen on the presumption that, while breathing air, ventilation would be stimulated and the carbon dioxide blown off. Campbell was fond of quoting Haldane's dictum that "intermittent oxygen therapy is like bringing a drowning man to the surface-occasionally". He argued that, because the body store of carbon dioxide was considerably greater than the store of oxygen, removal of oxygen during intermittent therapy would cause a much more rapid decline in oxygenation than in $\mathrm{PCO}_{2}$ and therefore would make matters worse as the hypoxia would be more severe than before oxygen treatment was instituted. He spent several years addressing the problem of optimal management of these patients. He argued that the ideal treatment was with controlled modest oxygen enrichment of inspired air as this would limit the potential rise in $\mathrm{PCO}_{2}$ and the degree of acidosis. Furthermore, because of the shape of the oxygen dissociation curve, even a small increase in inspired oxygen would produce a useful increase in oxygen content and consequent tissue supply. ${ }^{14}$ These considerations led him to use the principle of high airflow with oxygen enrichment in developing the Venturi mark, first described in $1960 .^{15}$ The prototype and early production models had a fixed Venturi orifice through which oxygen flowed at $2 \mathrm{l} /$ min, entraining a much larger flow of air via holes in the loose fitting mask; a second inlet was supplied with oxygen at varying flow in order to adjust the final concentration. In practice, this arrangement proved unsatisfactory and in a later modification, ${ }^{16}$ which subsequently became standard, a single nozzle was used with the different concentrations $(24 \%, 28 \%, 35 \%)$ provided by modifying the size of the Venturi orifice. The essential principle of these masks is that, over a relatively wide range of oxygen flows, the net concentration inspired by the patient remains reasonably constant, as increas- ing the flow of oxygen entrains a proportionally greater flow of air. The Venturi mask represents Campbell's most enduring practical contribution and remains in widespread use. Rather unfairly, he never received any royalties from its invention. ${ }^{1}$

Around the same time, Campbell and Howell developed a simple rebreathing method for estimating mixed venous (that is, pulmonary arterial) $\mathrm{PCO}_{2}{ }^{17}{ }^{18}$ This was at a time when blood gas electrodes were not generally available and arterial puncture was regarded by many as dangerous. Adapting earlier methods, they devised a simple two stage procedure in which the patient rebreathed from a small rubber bag containing $100 \%$ oxygen. Campbell also modified the classical Haldane apparatus for gas analysis to produce a simpler version for measurement of carbon dioxide only. ${ }^{19}$ The whole procedure of measurement and analysis could then be completed in 10 minutes. The $\mathrm{PCO}_{2}$ obtained is of "oxygenated" mixed venous blood which is a little higher than the $\mathrm{PCO}_{2}$ of true mixed venous blood because of the ChristiansenDouglas-Haldane effect-that is, the effect of increasing $\mathrm{PO}_{2}$ on the carbon dioxide dissociation curve. Initially it was proposed that subtracting $6 \mathrm{~mm} \mathrm{Hg}$ gave the best estimate of arterial $\mathrm{PCO}_{2}$. However, the shape of the carbon dioxide dissociation curve causes the mixed venous/arterial difference to widen as $\mathrm{PCO}_{2}$ rises and it was later shown that a more accurate estimate of $\mathrm{PaCO}_{2}$ is obtained by multiplying the rebreathing measurement by $0.8 .^{20}$ The method was popular in the 1960s and 1970s but was gradually replaced by direct arterial blood gas measurements. It retains the advantage of avoiding an arterial puncture and in some circumstances (such as transient hyperventilation) may give more representative information than a single arterial stab.

Later study of patients with respiratory failure with M W (Martin) $\mathrm{McNicol}^{21}$ confirmed theoretical predictions that, as long as patients were breathing air, the severity of hypercapnia and acidaemia was necessarily limited as they would die from hypoxia before lethal levels of $\mathrm{PaCO}_{2}$ or $\mathrm{pH}$ were attained. In previously untreated patients with hypercapnic respiratory failure due to acute exacerbations of COPD they found that only two of 81 had $\mathrm{PaCO}_{2}$ greater than $80 \mathrm{~mm} \mathrm{Hg}$ ( $10.7 \mathrm{kPa}$ ) and only four had an arterial $\mathrm{pH}$ less than 7.23. Any patients with greater hypercapnia or more severe acidosis had received oxygen in the ambulance or emergency department, important practical messages which are still relevant today.
As a result of his pioneering work on respiratory failure, Campbell had the honour of presenting two prestigious lectures-the Goulstonian of the Royal College of Physicians ${ }^{22}$ and the BurnsAmberson of the American Thoracic Society. ${ }^{23}$ In the former he gave an overview of respiratory failure with an analysis of its causes, defining it in terms of the two types familiar today. In passing he mentioned a couple of important practical clinical lessons: firstly, that there is no safe sedative in these patients and, secondly, that patients with COPD rarely develop peripheral oedema unless the $\mathrm{PaCO}_{2}$ is raised. He also emphasised that assessment of respiratory function was most important when the patient was at his best-in order to set the target for when he is at his worst-noting that "too often these measurements are made only when a patient is in relapse, at a time when it is only too obvious what one is fighting against, whereas one wishes to know what one is fighting for". He was the first non-American to deliver the Burns-Amberson lecture ${ }^{23}$ in which he focused on exacerbations of COPD, expanding on the data of McNicol and Campbell ${ }^{21}$ and emphasising particularly that intubation and tracheostomy could usually be avoided by careful initial management, especially of oxygen therapy. In relation to the more frequent use of mechanical ventilation in North America, he commented, characteristically "in some institutions it is easier to get nurses to look after machines than after patients". He concluded "the patient with acute on chronic respiratory failure due to obstructive bronchitis and emphysema does not usually represent too difficult a problem provided he is carefully managed from the beginning. He can deteriorate dramatically if oxygen therapy is mismanaged and experience of success in the salvage of mismanaged patients should not be uncritically applied to the initial treatment." This admonition continues to resonate in the era of non-invasive ventilation.

The other major group contributing to the management of respiratory failure in Britain in the 1960s was based in Edinburgh, led by D C (David) Flenley. In $1963,{ }^{24}$ comparing the performance of their own low flow oxygen mask (later known as the Edinburgh mask) with the Venturi mask, they showed that early production models of the latter gave less accurate inspired oxygen concentrations than claimed in Campbell's original paper, ${ }^{15}$ a point subsequently acknowledged by Campbell. ${ }^{16}$ Further clinical data from Edinburgh $^{25}$ pointed to the need to 
measure not only $\mathrm{PaCO}_{2}$, but also $\mathrm{PaO}_{2}$ and $\mathrm{pH}$. The authors also showed that, in practice, performance of the Edinburgh mask was as good as that of the early Venturi masks (and their masks were cheaper!). These areas of disagreement led to an increasingly tetchy exchange of letters in the $B M J .{ }^{162627}$ Reading this correspondence 40 years later, one is struck more by the areas of agreement than the disagreements. Both groups emphasised the need to control inspired oxygen concentration in the early management of acute hypercapnic respiratory failure, both agreed that only modest enrichment of inspired air was desirable, and both taught that oxygen treatment should be continuous rather than intermittent. The areas of disagreement centred on the need (or not) to measure $\mathrm{pH}$ and $\mathrm{PaO}_{2}$, the (still unanswered) question "what is a safe arterial $\mathrm{PO}_{2}$ ?", and the performance of the two types of mask. The aim in managing these patients is to control the inspired oxygen concentration which, in principle, a Venturi mask should do; simply controlling oxygen flow (through a nonVenturi device) inevitably gives less precise control of the inspired concentration. Other areas of dispute related more to pragmatic issues and, in particular, the contemporary poor availability of blood gas electrodes. The Edinburgh criticism of Campbell's cautious stepwise approach to oxygen therapy (using $24 \%$ and then $28 \%$ if necessary) was shown subsequently to be unfounded. ${ }^{28}$ On the other hand, few clinicians would now be as unconcerned about the need to measure $\mathrm{PaO}_{2}$ as was Campbell, and the value of arterial pH measurements has been amply demonstrated by subsequent experience, not least by later data from Edinburgh. $^{29}$

Lessons learned are not always remembered, however. ${ }^{30}$ Campbell's teaching on the limits of hypoxaemia and acidosis in acute respiratory failure remains valid-but only in patients who have not received oxygen. Unfortunately, the problems of oxygen induced progressive hypercapnia in these patients are still all too common, especially as a consequence of treatment in ambulances and emergency departments. $^{31} 32$

One area of clinical physiology in which Campbell was less successful was his attempt to bury the concept of $\mathrm{pH}($ ("RIpH"33) and to replace it with the more user friendly hydrogen ion concentration. Unfortunately, $\mathrm{pH}$ survived and has continued to baffle generations of medical students! Perhaps in the era of nanotechnology, the concept of a nanomolar concentration might now prove more acceptable and might help to demystify the field of acid base balance.

\section{CLINICAL SCIENCE AND MEDICAL EDUCATION}

In his later career Campbell took a major interest in medical education. Related to this were his views on the diagnostic process as employed by experienced clinicians and the potential applicability of the ideas of the philosopher, Karl Popper, to clinical medicine. In Popper's view, science consists of making conjectures and testing these experimentally in an attempt to falsify or refute them. ${ }^{34}$ This differs from the classical Baconian theory of induction according to which observation is followed by logical inferences. Campbell extended Popper's thinking into the area of clinical medicine, pointing out that the clinical encounter essentially follows a similar scientific sequence: the experienced clinician does not start with a "blank mind"; rather, diagnostic ideas (hypotheses) arise at an early stage in the interview and he then looks for ways to refute them, either by clinical examination or investigation..$^{35}$ In this sense, Campbell claimed that criticism that modern medicine was suffering from "too much science" were misdirected due to confusing science with technology; on the contrary, there is too little science in clinical medicine rather than too much. ${ }^{36}$

Campbell emphasised that the validity of a science is not necessarily greater just because it appears to be more basic. Regretting that "the medical curriculum, the reward structure of the scientific community, the contents of journals of clinical research all bear witness to "the more basic the better"', he proposed "this attitude must be challenged". He argued strongly that, since the strength of a science resided in the "rigour of its own empiricism", clinical science is no less valid than more basic disciplines. ${ }^{3}$ Although these opinions were voiced 25 years ago, they are even more pertinent today.

The implications of these views for medical education are considerable. Thus, Campbell argued that students should encounter diagnostic problems at an early stage in their undergraduate career in order to acquire the habit of testing and refining hypotheses; traditional clinical skills of history taking and comprehensive examination should not be overdone; rather than teaching what we think we should teach, we should teach what we do, since economy is as important as thoroughness; the implications of investigations should be considered in advance in order to avoid generating unhelpful information and the "mindless work-up" should be avoided. ${ }^{35}$ Some of these provocative ideas are being put into effect in modern medical curricula but, on a currently topical note, Campbell also cautioned against pressures to curtail curricula in order to produce more practitioners. Just as it is mistaken to confuse technology with science, so it is to equate training with education. ${ }^{37} \mathrm{He}$ expressed concern that too much emphasis on training would weaken the influence of science in medicine, concluding "just as it is essential for the students to meet doctors behaving as doctors, so it is essential for them to meet scientists behaving as scientists. The student and the scientist must be brought together for a grander purpose than the passive transfer of acceptable stories". This involves a careful balance between "stocking and engaging the minds of students". ${ }^{38}$

\section{OTHER CONTRIBUTIONS}

In this brief review I have omitted many of Campbell's other noteworthy contributions to respiratory medicine. These include his extensive work with $\mathrm{N}$ L (Norman) Jones on the physiology of exercise and the clinical use of exercise tests; $^{39}{ }^{40}$ the development of a simple method for assessing the ventilatory response to hypoxia; ${ }^{41}$ and his research on the mechanisms and information content of the physical signs elicited by respiratory examination..$^{42}{ }^{43}$ Not least of his many important contributions to the literature is the fascinating account of his personal experiences as a manic depressive, and particularly the Joycean "stream of consciousness" neologisms of the hypomanic state. He summed up the contrast between the two states of mind and others' reactions to them: "when you're low, you feel terrible that others are happy because you're quiet and well behaved. When you're high, you could conquer the universe but all that everyone else is thinking about is how to get you down to earth again".

In recognition of his many contributions to respiratory medicine, the BTS plans to establish a biannual Moran Campbell lecture on a subject related either to clinical physiology or medical education.

\section{ACKNOWLEDGEMENTS}

I am grateful to Professor Jack Howell for helpful comments on the manuscript.

Thorax 2004;59:737-740.

doi: 10.1136/thx.2004.032219

Correspondence to: Professor G J Gibson, Department of Respiratory Medicine, Freeman Hospital, Newcastle upon Tyne NE7 7DN, UK; g.j.gibson@ncl.ac.uk 


\section{REFERENCES}

1 Campbell EJM. Not always on the level. London: The Memoir Club, BMJ, 1988.

2 Campbell EJM, Dickinson CJ. Clinical physiology Oxford: Blackwell, 1960.

3 Campbell EJM. Clinical science. Ciba Foundation Symp No. 44, 1976:41-52.

4 Campbell EJM. Book review. BMJ 1961;1:1444

5 Campbell EJM, Green JH. The variations in intraabdominal pressure and the activity of the abdominal muscles during breathing; a study in man. J Physiol 1953;122:282-90.

6 Campbell EJM. An electromyographic examination of the role of the intercostal muscles in breathing in man. J Physiol 1955; 129:12-26.

7 Campbell EJM, Friend J. Action of breathing exercises in pulmonary emphysema. Lancet 1955;i:325-9.

8 Campbell EJM. The role of the scalene and sternomastoid muscles in breathing in norma subjects; an electromyographic study. J Anat 1955:89:378-86

9 Campbell EJM. The respiratory muscles. London: Lloyd-Luke, 1958

10 Campbell EJM, Howell JBL. The sensation of breathlessness. Br Med Bull 1963:19:36-40.

11 Campbell EJM, Freedman S, Clark TJ, et al. The effect of muscular paralysis induced by tubocurarine on the duration and sensation of breath-holding. Clin Sci 1967;32:425-32.

12 Campbell EJM, Howell JBL. The sensation of dyspnoea. BMJ 1963;2:868

13 Campbell EJM. The evaluation of dyspnoea. Trans Med Soc Lond 1975-7, 92-93:13-7.

14 Campbell EJM. Respiratory failure: the relation between oxygen concentrations of inspired air and arterial blood. Lancet 1960;ii:10-11.

15 Campbell EJM. A method of controlled oxygen administration which reduces the risk of carbondioxide retention. Lancet 1960;ii:12-14.
16 Campbell EJM. Apparatus for oxygen administration. BMJ 1963;2:1269-70

17 Campbell EJM, Howell JBL. Simple rapid methods of estimating arterial and mixed venous $\mathrm{PCO}_{2}$. BMJ 1960;2:458-62.

18 Campbell EJM, Howell JBL. Rebreathing method for measurement of mixed venous $\mathrm{PCO}_{2}$. BMJ 1962;2:630-3.

19 Campbell EJM. Simplification of Haldane's apparatus for measuring carbon dioxide concentration in respired gases in clinica practice. BMJ 1960;1:457-8.

20 McEvoy JD, Jones NL, Campbell EJM. Mixed venous and arterial $\mathrm{PCO}_{2}$. BMJ 1974:4:687-90.

21 McNicol MW, Campbell EJM. Severity of respiratory failure: arterial blood-gases in untreated patients. Lancet 1965;ii:336-8.

22 Campbell EJM. Respiratory failure. BMJ 1965:1:1451-60.

23 Campbell EJM. The J. Burns Amberson lecture. The management of acute respiratory failure in chronic bronchitis and emphysema. Am Rev Respir Dis 1967:96:626-39.

24 Flenley DC, Hutchison DCS, Donald KW Behaviour of apparatus for oxygen administration. BMJ 1963;2:1081-8.

25 Hutchison DCS, Flenley DC, Donald KW. Controlled oxygen therapy in respiratory failure. BMJ 1964;2:1 159-66.

26 Campbell EJM. Management of respiratory failure. BMJ 1964:2:1328

27 Donald KW, Hutchison DCS, Flenley DC. Management of respiratory failure. BM 1964;2:1461-2.

28 Warrell DA, Edwards RHT, Godfrey S, et al. Effect of controlled oxygen therapy on arterial blood gases in acute respiratory failure. $B M$ 1970;1:452-5.

29 Jeffrey AA, Warren PM, Flenley DC. Acute hypercapnic respiratory failure in patients with chronic obstructive lung disease: risk factors and use of guidelines for management. Thorax 1992:47:34-40.
30 Davies RJO, Hopkin JM. Nasal oxygen in exacerbations of ventilatory failure: an under appreciated risk. BMJ 1989;299:43-4.

31 Plant PK, Owen JL, Elliott MW. One year period prevalence study of respiratory acidosis in acute exacerbations of COPD: implications for the provision of non-invasive ventilation and oxygen administration. Thorax 2000;55:550-4.

32 Durrington HJ, Ramsay CF, Howard LSGE, et al. Initial oxygen management in patients with COPD. Thorax. 2003;58: iii 22, (Suppl III).

33 Campbell EJM. RlpH. Lancet 1962;i:681-3.

34 Popper KR. Conjectures and refutations: the growth of scientific knowledge. London: Routledge and Paul, 1962.

35 Campbell EJM. The diagnosing mind. Lancet 1987;i:849-51.

36 Campbell EJM. Basic science, science, and medical education. Lancet 1976;i:134-6.

37 Campbell EJM. On education and training. Lancet 2000;356:1116.

38 Campbell EJM. Clinical science. Clin Sci Mol Med 1976:51:1-7.

39 McHardy GJ, Jones NL, Campbell EJM Graphical analysis of carbon dioxide transport during exercise. Clin Sci 1967;32:289-98.

40 Killian KJ, Leblanc P, Martin DH, et al. Exercise capacity and ventilatory, circulatory, and symptom limitation in patients with chronic airflow limitation. Am Rev Respir Dis 1992; 146:935-40

41 Rebuck AS Campbell EJM. A clinical method for assessing the ventilatory response to hypoxia. Am Rev Respir Dis 1974;109:345-50.

42 Godfrey S, Edwards RHT, Campbell EJM, et al Clinical and physiological associations of some physical signs observed in patients with chronic airways obstruction. Thorax 1970;25:285-7.

43 Stubbing DG, Mathur PN, Roberts RS, et al. Some physical signs in patients with chronic airflow obstruction. Am Rev Respir Dis 1982; 125:549-52.

\section{Call for papers}

10th European Forum on Quality Improvement in Health Care 13-15 April 2005, ExCel, Docklands, London For further information on how to submit your paper please go to: http://www.quality.bmipg.com 